\title{
Adenosine and ATP Affect LPS-Induced Cytokine Production in Canine Macrophage Cell Line DH82 Cells
}

\author{
Yuka FUJIMOTO ${ }^{1}$, Naoko NAKATANI ${ }^{1)}$, Takeya $\mathrm{KUBO}^{2)}$, Yuko SEMI ${ }^{2}$, Natsuho YOSHIDA ${ }^{2)}$, \\ Hidemitsu NAKAJIMA ${ }^{2)}$, Toshie ISERI ${ }^{1)}$, Yasu-Taka AZUMA ${ }^{2) *}$ and Tadayoshi TAKEUCHI ${ }^{2)}$ \\ ${ }^{1)}$ Laboratory of Advanced Diagnosis and Treatment, Division of Veterinary Science, Graduate School of Life and Environmental Science, \\ Osaka Prefecture University, Izumisano, Osaka 598-8531, Japan \\ ${ }^{2)}$ Laboratory of Veterinary Pharmacology, Division of Veterinary Science, Graduate School of Life and Environmental Science, Osaka \\ Prefecture University, Izumisano, Osaka 598-8531, Japan
}

(Received 12 May 2011/Accepted 15 August 2011/Published online in J-STAGE 29 August 2011)

\begin{abstract}
Macrophages are essential for controlling the majority of infections, and are mediators of natural immunity. During infection, lipopolysaccharide (LPS) stimulates macrophages to produce pro-inflammatory cytokines. Adenosine and ATP released into the extracellular space by immunological stimuli have been shown to regulate various immune functions. More recently, it has been shown adenosine and ATP have a critical role on the physiological negative feedback mechanism for limitation and termination of tissue-specific and systemic inflammatory responses. It was useful and meaningful to gain information about interaction between LPS, which generates the inflammation, and adenosine and ATP, which terminate the inflammation. We evaluate effects of adenosine and ATP on the production of cytokines related to inflammation in canine macrophage cell line DH82 cells. Adenosine and ATP respectively increased the production of IL-10 without affecting the production of IL-6, TNF- $\alpha$ and IL-12 in DH82 cells. In addition, adenosine and ATP prevented the production of LPS-induced IL-6, TNF- $\alpha$ and IL-12 in DH82 cells. In contrast, adenosine and ATP potentiated LPS-induced IL-10 production in DH82 cells. Moreover, adenosine, but not ATP inhibited LPS-induced expression of TLR4 in DH82 cells. These results suggest that conditions related to increased adenosine and/or ATP may play an important role in the inflammatory reactions.

KEY WORDS: adenosine, ATP, cytokine, LPS, macrophage.
\end{abstract}

doi: 10.1292/jvms.11-0228; J. Vet. Med. Sci. 74(1): 27-34, 2012

Macrophages are commonly the first cells of the immune system to encounter invaders such as bacteria and fungi, and are ready to leave the circulation and attack the intruder at any place and at any time. During infection, lipopolysaccharide (LPS), a predominant glycolipid in the outer membrane of Gram-negative bacteria, stimulates macrophages to produce inflammatory cytokines. Namely, macrophages are main cells to secrete inflammatory cytokines TNF- $\alpha$ and IL6 . In addition, macrophages produce IL-12 and IL-10 which both bridge the gap between innate and acquired immunity. Indeed, macrophages not only are involved in inflammatory responses through the production of TNF- $\alpha$ and IL- 6 but also influence the Th1/Th2 balance through the production of IL-12 and IL-10.

LPS induces cellular responses by its complexing with circulating LPS-binding protein and subsequent binding to CD14 that, in turn, facilitates the interaction of LPS with signaling molecules belonging to the Toll-like receptor 4 (TLR4) [34, 35]. Adenosine is a purine nucleotide that is released from a variety of cells in response to metabolic stress or from the sympathetic nervous system, and occupies various adenosine receptor subtypes on target cells. Adenosine is known to bind four different types of G-protein

\footnotetext{
* Correspondence to: Azuma, Y.T., Laboratory of Veterinary Pharmacology, Osaka Prefecture University, 1-58 Rinku-ohraikita, Izumisano, Osaka 598-8531, Japan.

e-mail: azuma@vet.osakafu-u.ac.jp.
}

(C)2012 The Japanese Society of Veterinary Science coupled cell surface receptors, A1, A2a, A2b and A3 adenosine receptors [24]. In addition, the accumulation of extracellular adenosine in inflamed and damaged tissues [8, $18,26,31,33]$ and the immunosuppressive properties of cAMP-elevating adenosine receptors indicate that signaling by $\mathrm{A} 2 \mathrm{aR}$ on immune cells is a possible natural mechanism of inhibition and/or termination of inflammation $[4,5,7,9$, $14,15,27]$. Recently, it has been shown that activation of $\mathrm{A} 2 \mathrm{aR}$ is a critical part of the physiological negative feedback mechanism for limitation and termination of tissuespecific and systemic inflammatory responses [23]. In contrast, ATP and purinergic receptor P2X7 are implicated in signaling between macrophages and other cells involved in the immune response and target cells [28]. Stimulation of the P2X7 receptor with high concentrations of ATP triggers influx of $\mathrm{Ca}^{2+}$ and $\mathrm{Na}^{+}$, and efflux of $\mathrm{K}^{+}$, followed by the formation of non-selective plasma membrane pores, resulting in cell swelling, vacuolization, and cell death [6]. It has been shown that extracellular ATP is not stable, and ATP is readily degraded to adenosine by ectonucleotidases.

Since, inappropriate or prolonged inflammation is the main cause of many diseases, it is important to understand the physiological mechanisms that alter inflammatory responses. Especially, it was useful and meaningful to gain information about interaction between LPS and adenosine or ATP; the former generates the inflammation and the latter terminates the inflammation. Although previous studies indicated that adenosine and ATP alter the LPS-mediated 
production of cytokines, these previous studies were demonstrated in human, rat, mouse macrophages. Very little, if anything, is known about the ability of adenosine or ATP on the cytokine production by LPS in canine macrophages. To evaluate possible abilities of adenosine and ATP on inflammatory responses by canine macrophages under the presence of bacterial pathogen such as LPS, we have simultaneously examined effects of adenosine and ATP on the production of IL- 6 , TNF- $\alpha$, IL-12 and IL-10 by LPStreated canine macrophages. In addition, we also investigated the ability of adenosine on the expression of TLR4 in canine macrophages.

\section{MATERIALS AND METHODS}

Materials: Adenosine, ATP, and LPS from E. coli [0111:B4] were provided by Sigma (St. Louis, MO, U.S.A.).

Cell Culture: Canine macrophage cell line DH82 cells (DS Pharma Biomedical, Osaka, Japan) was maintained in aMEM supplemented with $10 \%$ FBS, 100 units $/ \mathrm{m} l$ of penicillin and $100 \mu \mathrm{g} / \mathrm{m} l$ of streptomycin.

Proliferation assay: Cell proliferation was evaluated by CellTiter $96^{\circledR} \mathrm{AQ}_{\text {ueous }}$ One Solution Cell Proliferation Assay (Promega Corporation; Madison, WI) [3]. Briefly, cells (1 $\times 10^{5}$ ) were incubated with adenosine, ATP or LPS in 96well culture plates for $18 \mathrm{hr}$. After incubation, MTS solution was added to culture plates. The absorbance at a wavelength of $490 \mathrm{~nm}$ was measured at $1 \mathrm{hr}$ after the addition of MTS solution, and reference absorbance is $690 \mathrm{~nm}$.

Quantitative real-time PCR: Cytokine production assay was performed as previously described [1]. In brief, cells (3 $\times 10^{6}$ ) were incubated with adenosine, ATP or LPS in $4 \mathrm{~cm}$ culture dishes for 4,8 and $18 \mathrm{hr}$. Total RNA was extracted from each tissue using TRIzol Reagent (Life Technologies Japan, Tokyo, Japan). RNA was used to synthesize complementary cDNA using SuperScript Reverse Transcriptase (Roche, Mannheim, Germany). The primer sets used were as follows: 5'- GAACTCCCTCTCCACAAGC-3' and 5'TTCTTGTCAAGCAGGTCTCC-3' for IL-6, 5' - ACCACACTCTTCTGCCTGCT-3' and 5'- CTGGTTGTCTGTCAGCTCCA-3' for TNF- $\alpha$, 5'-GGCAAAGAATTATTCT GGACGTT-3' and 5'-GAAGCCTCTGCTACTTTTGACACT-3' for IL-12, 5'-GACAAGCTGGACAACATACTGCTGACC-3' and 5'-TCCTAGAGTCGAGAAGAG TTGCCATCC-3' for IL-10, 5' - CAAAATCCCCAACAACATCC-3' and 5' - TGGTTTAGGCCCTGATATGC-3' for TLR4, 5'- GGAGAAAGCTGCCAAATATG-3' and 5'ACCAGGAAATGAGCTTGACA-3' for GAPDH. Realtime PCR was performed using SYBR Green (Toyobo, Osaka, JAPAN). Amplification of GAPDH mRNA was used for each experimental sample as an endogenous control to account for differences in the amount and quality of total RNA added to each reaction.

Statistical analysis: Result were expressed as the mean \pm SE. Statistical analysis was determined by one-way ANOVA for non-repeated to detect differences between
(A) IL-6

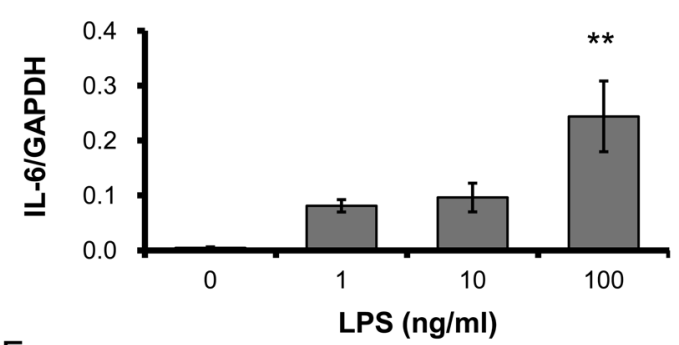

TNF- $\alpha$

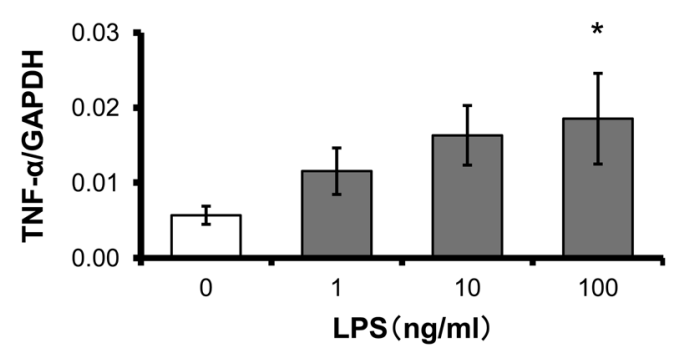

(B)

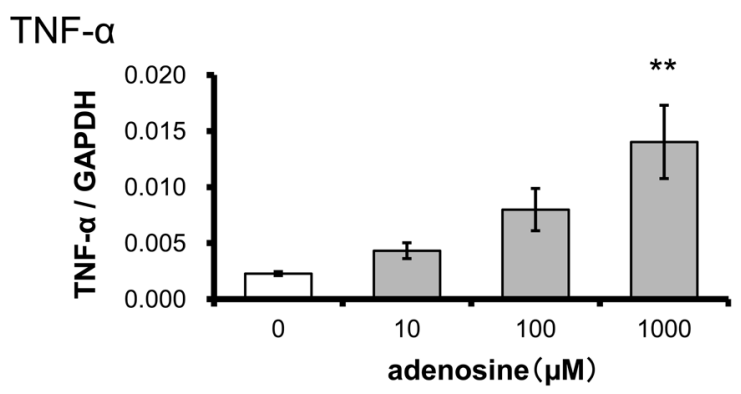

Fig. 1. Abilities of LPS and adenosine on the cytokine production in DH82 cells. DH82 cells were allowed to adhere to plates for $30 \mathrm{~min}$. Adherent DH82 cells were incubated with LPS (A) or adenosine (B) for $18 \mathrm{hr}$. The data from four different specimens are shown. The expression of IL-6, TNF- $\alpha$ and GAPDH was examined by quantitative real-time PCR. The level of IL-6 mRNA and TNF- $\alpha$ mRNA in the DH82 cells is given as the fold increase relative to the level of GAPDH mRNA in the DH82 cells. ${ }^{*} P<0.05, * * P<0.01$, when compared with untreated DH82 cells.

multiple groups. Difference between groups was determined by Dunnett' test or Student-Newman-Keuls (SNK) test. Differences were considered to be significant when the $\mathrm{P}$ value was $<0.05$.

\section{RESULTS}

Effects of adenosine, ATP and LPS on the proliferation: We first assessed effects of adenosine, ATP and LPS on the proliferation in DH82 cells. Addition of LPS significantly increased the proliferation at $18 \mathrm{hr}$ after incubation (data not shown). Similarly, adenosine and ATP significantly increased the proliferation (data not shown). However, adenosine- and ATP-induced proliferation failed to result in the significant difference from LPS-induced proliferation. 
(A)

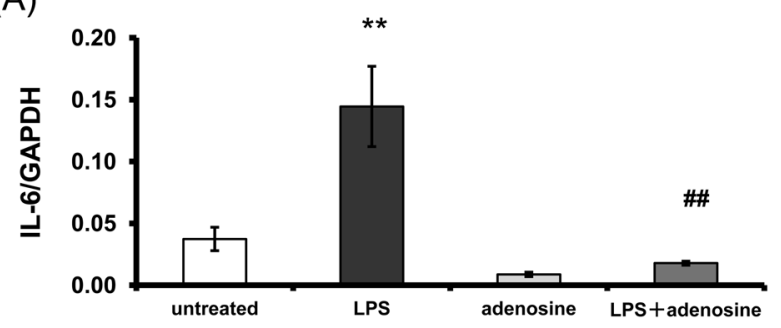

(B)

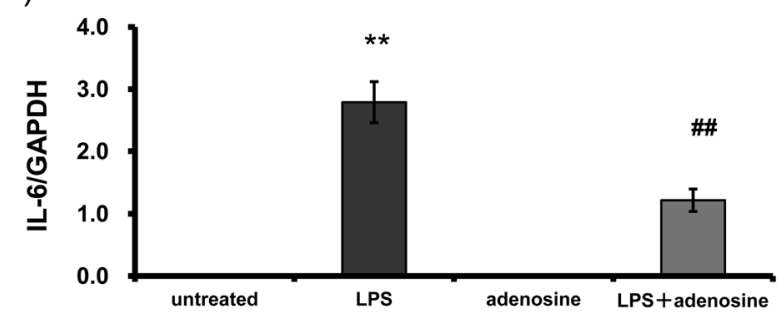

(C)

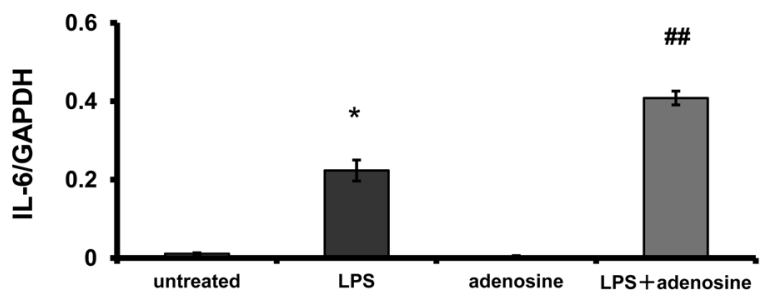

(D)

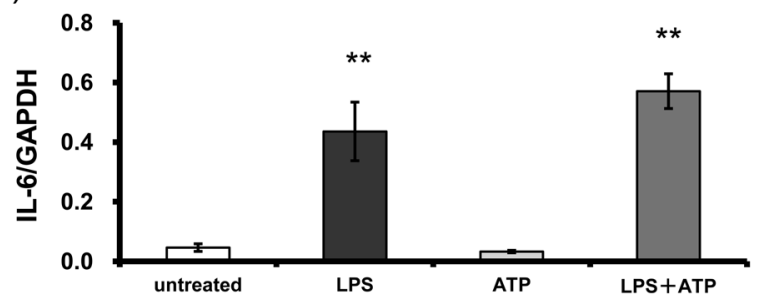

(E)

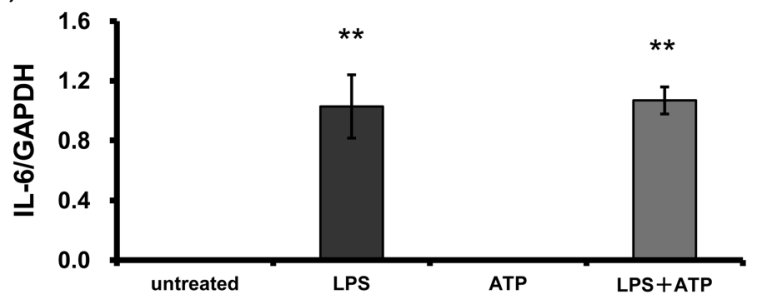

(F)

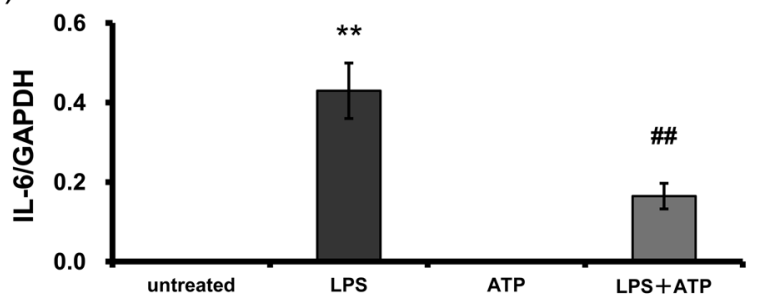

Fig. 2. Abilities of adenosine and ATP on the production of IL-6 in DH82 cells. DH82 cells were allowed to adhere to plates for 30 min. Adherent DH82 cells were incubated with adenosine or ATP in either the absence or presence of LPS for 4 (A, D), 8 (B, E) and 18 (C, F) hr. The data from 3 to 6 different specimens are shown. The expression of IL- 6 and GAPDH was examined by quantitative real-time PCR. The level of IL-6 mRNA in the DH82 cells is given as the fold increase relative to the level of GAPDH mRNA in the DH82 cells. ${ }^{*} P<0.05, * *$ $P<0.01$, when compared with untreated DH82 cells. ${ }^{\#} P<0.01$, when compared with LPS-treated DH82 cells.

Effects of adenosine and LPS on the cytokine production: LPS at $100 \mathrm{ng} / \mathrm{ml}$ resulted in a potentiation of IL-6 and TNF- $\alpha$ production byDH82 cells at $18 \mathrm{hr}$ after incubation (Fig. 1A). In addition, adenosine at $1000 \mu \mathrm{M}$ resulted in a potentiation of TNF- $\alpha$ production byDH82 cells at $18 \mathrm{hr}$ after incubation (Fig. 1B). This suggested the importance of adenosine and ATP in addition to LPS during inflammatory responses. To determine the effect of combination of adenosine and LPS, or ATP and LPS on the cytokine production, DH82 cells were co-treated with adenosine or ATP in the presence of LPS at $100 \mathrm{ng} / \mathrm{m} l$ for 4,8 and $18 \mathrm{hr}$.

IL-6 production: LPS at $100 \mathrm{ng} / \mathrm{m} l$ resulted in a potentiation of IL- 6 production by DH82 cells at 4, 8 and $18 \mathrm{hr}$ after incubation (Fig. 2). However, adenosine at $1,000 \mu \mathrm{M}$ and ATP at $1000 \mu \mathrm{M}$ failed to increase the production of IL- 6 by DH82 cells (Fig. 2). In addition, adenosine caused an inhibition of LPS-induced IL- 6 production at 4 and $8 \mathrm{hr}$ after incubation (Fig. 2A, 2B). At $18 \mathrm{hr}$ after incubation, interestingly, the effect of adenosine on LPS-induced IL-6 production caused a potentiation rather than inhibition (Fig. 2C). In contrast, ATP failed to alter LPS-induced IL-6 production at 4 and $8 \mathrm{hr}$ after incubation (Fig. 2D, 2E). At $18 \mathrm{hr}$ after incubation, ATP caused an inhibition of LPS-induced

\section{IL-6 production (Fig. 2F).}

$T N F-\alpha$ production: LPS at $100 \mathrm{ng} / \mathrm{m} /$ resulted in a potentiation of TNF- $\alpha$ production by DH82 cells at 4,8 and $18 \mathrm{hr}$ after incubation (Fig. 3). However, ATP at $1000 \mu \mathrm{M}$ failed to increase the production of TNF- $\alpha$ by DH82 cells (Fig. 3). In addition, adenosine and ATP caused an inhibition of LPS-induced TNF- $\alpha$ production at 4,8 and $18 \mathrm{hr}$ after incubation (Fig. 3A, 3B, 3D, 3E, 3F). Interestingly, the effect of adenosine on LPS-induced TNF- $\alpha$ production caused a potentiation rather than inhibition at $18 \mathrm{hr}$ after incubation (Fig. 3C).

IL-12 production: LPS at $100 \mathrm{ng} / \mathrm{m} l$ resulted in a potentiation of IL-12 production by DH82 cells at 4, 8 and $18 \mathrm{hr}$ after incubation (Fig. 4). However, adenosine at $1000 \mu \mathrm{M}$ and ATP at $1,000 \mu \mathrm{M}$ failed to increase the production of IL-12 by DH82 cells (Fig. 4). Adenosine caused an inhibition of LPS-induced IL-12 production at 4, 8 and $18 \mathrm{hr}$ after incubation (Fig. 4A, 4B, 4C). In addition, ATP caused an inhibition of LPS-induced IL-12 production at $4,8 \mathrm{hr}$, but not $18 \mathrm{hr}$ (Fig. 4D, 4E, 4F).

IL-10 production: LPS at $100 \mathrm{ng} / \mathrm{m} l$ resulted in a potentiation of IL-10 production by DH82 cells at 4, 8 and $18 \mathrm{hr}$ after incubation (Fig. 5). Adenosine at $1000 \mu \mathrm{M}$ and ATP at 
(A)

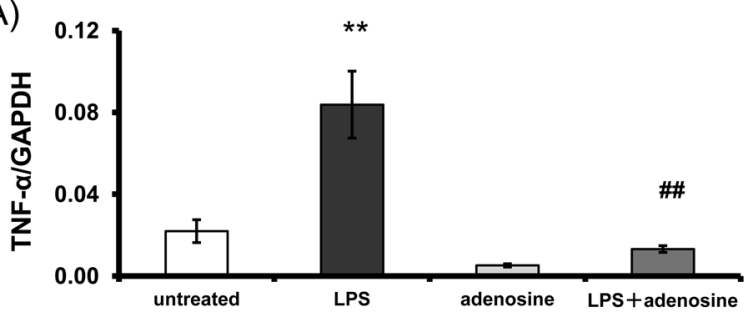

(B)

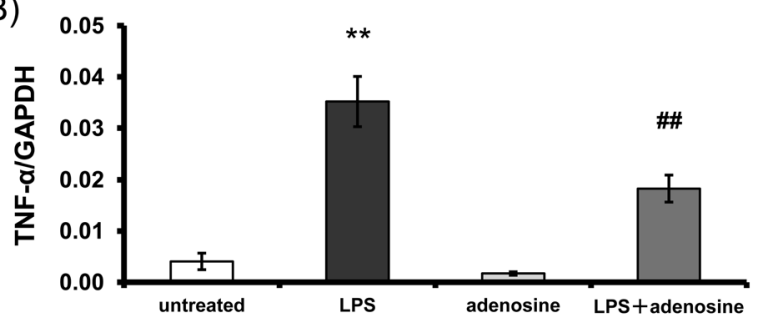

(C)

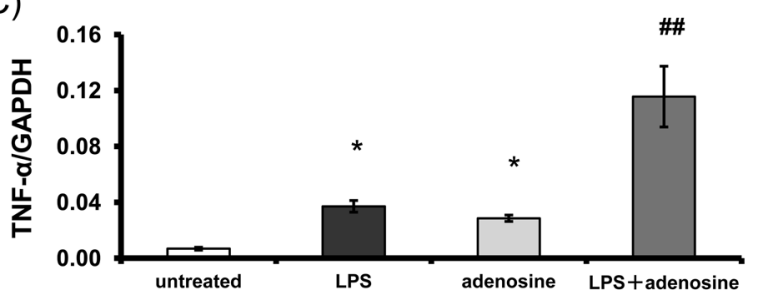

(D)

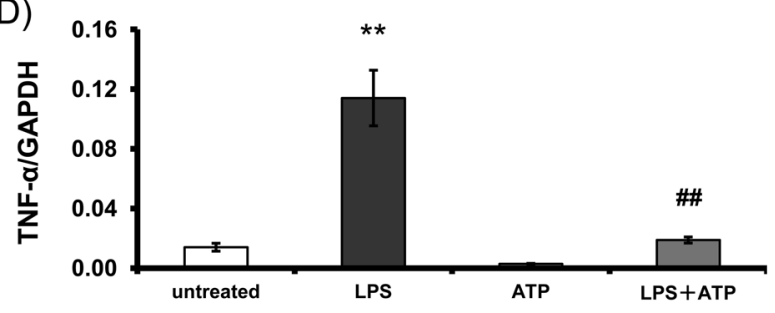

(E)

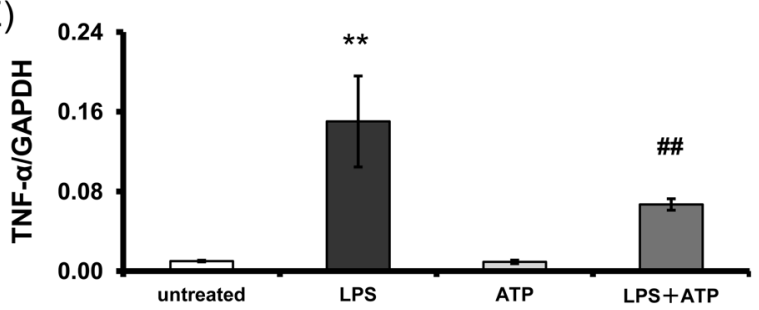

$(\mathrm{F})$

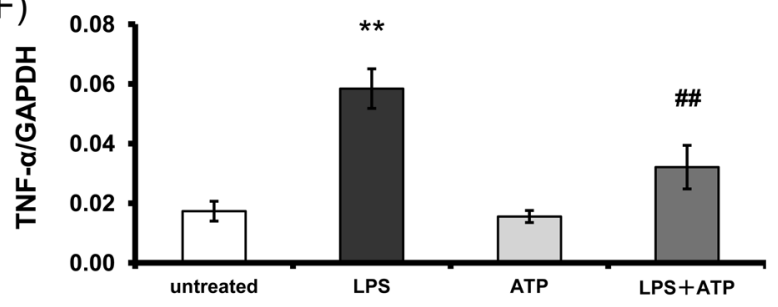

Fig. 3. Abilities of adenosine and ATP on the production of TNF- $\alpha$ in DH82 cells. DH82 cells were allowed to adhere to plates for 30 min. Adherent DH82 cells were incubated with adenosine or ATP in either the absence or presence of LPS for 4 (A, D), 8 (B, E) and 18 (C, F) hr. The data from 3 to 7 different specimens are shown. The expression of TNF- $\alpha$ and GAPDH was examined by quantitative real-time PCR. The level of TNF- $\alpha$ mRNA in the DH82 cells is given as the fold increase relative to the level of GAPDH mRNA in the DH82 cells. * $P<0.05$, ** $P<0.01$, when compared with untreated DH82 cells. ${ }^{\#} P<0.01$, when compared with LPS-treated DH82 cells.

$1000 \mu \mathrm{M}$ increased the production of IL-10 by DH82 cells at $8 \mathrm{hr}$ after incubation (Fig. 5). In marked contrast to IL-6, TNF- $\alpha$ and IL-12 production, adenosine and ATP significantly potentiated LPS-induced IL-10 production (Fig. 5).

Expression of TLR4: Next, we examined whether adenosine, ATP and LPS affect the expression of TLR4 in DH82 cells. On the expression of TLR4, LPS potentiated the expression of TLR4 at $4 \mathrm{hr}$ after incubation (Fig. 6). However, adenosine and ATP did not affect the expression of TLR4. In addition, adenosine, but not ATP caused an inhibition of LPS-induced TLR4 expression (Fig. 6).

\section{DISCUSSION}

In this study we demonstrated that adenosine and ATP are effective to alter the production of cytokines in LPSstimulated canine macrophages. Our findings emphasize that effects of adenosine and ATP were evident under the condition of that DH82 cells were given LPS at $100 \mathrm{ng} / \mathrm{ml}$. As shown previously, stimulation of A1 and A2 adenosine receptors resulted in an inhibition of the production of TNF$\alpha$ and IL-10 in mouse macrophage treated with LPS at 100 $\mu \mathrm{g} / \mathrm{m} l$ for $24 \mathrm{hr}$ [11]. Stimulation of A3 adenosine receptor inhibited IL-12 production in mouse macrophage treated with LPS $10 \mu \mathrm{g} / \mathrm{m} l$ and IFN $\gamma$ for $24 \mathrm{hr}$, and inhibited IL-6 production by mouse macrophage treated with LPS $10 \mu \mathrm{g} /$ $\mathrm{m} l$ for $24 \mathrm{hr}$ [29]. Stimulation of adenosine receptor suppressed the production of TNF- $\alpha$ and IL- $1 \beta$ by human bone marrow-derived macrophages treated with IFN $\gamma$ for $24 \mathrm{hr}$ [36]. Similarly, adenosine have been shown to inhibit the production of TNF- $\alpha$ and IL-12 by mouse macrophages treated with LPS at $10 \mu \mathrm{g} / \mathrm{m} l$ for $24 \mathrm{hr}$ [12]. In contrast, stimulation of A1, A2, and A3 adenosine receptors all potentiated IL-10 production but inhibited IL-12 production by human monocyte treated with LPS at $1 \mu \mathrm{g} / \mathrm{m} l$ for $18 \mathrm{hr}$ [17]. Namely, adenosine decreased the production of inflammatory cytokine including IL- $1 \beta$, IL-6, TNF- $\alpha$, IL-12 in both human and mouse macrophages. Although adenosine prevented the production of IL- 6 , TNF- $\alpha$, and IL-12 in canine macrophages in this study as well as human and mouse macrophages, it is perhaps more interesting to ask why adenosine potentiated the production of IL- 6 and TNF$\alpha$ at only $18 \mathrm{hr}$ after incubation. One reasonable explanation is due to the species difference between human and mouse, and canine. Although these previous studies indicated that adenosine and ATP alter the LPS-mediated production of 
(A)

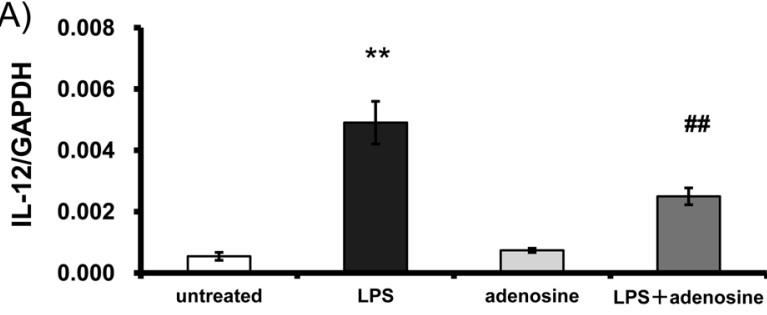

(B)

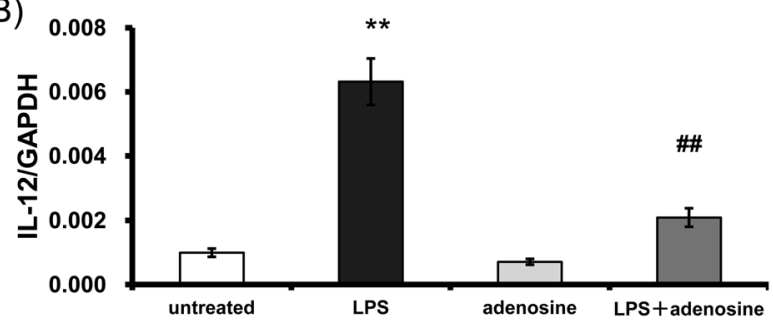

(C)

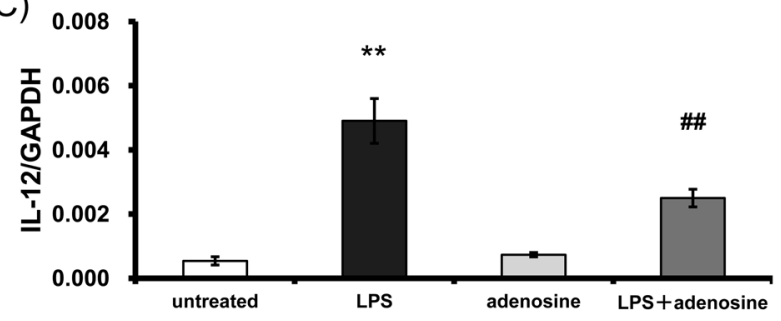

(D)

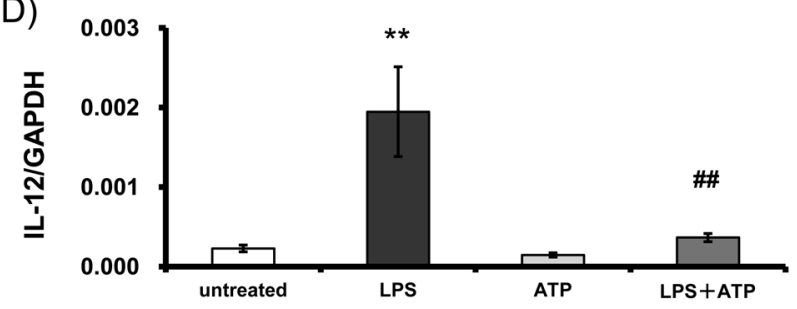

(E)

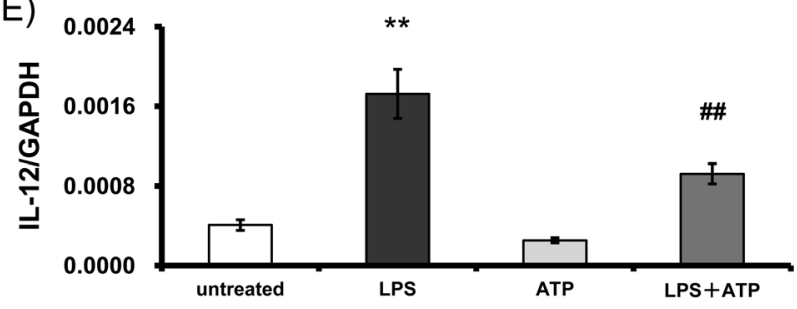

(F)

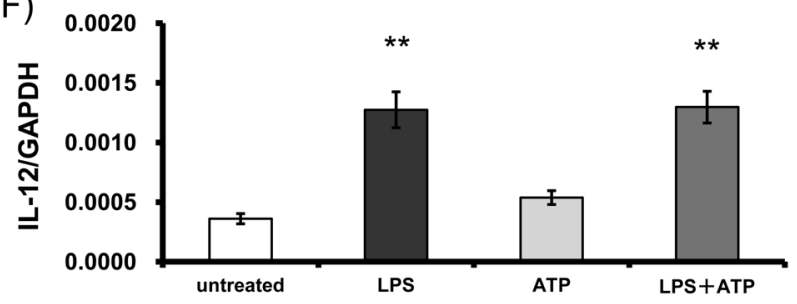

Fig. 4. Abilities of adenosine and ATP on the production of IL-12 in DH82 cells. DH82 cells were allowed to adhere to plates for 30 min. Adherent DH82 cells were incubated with adenosine or ATP in either the absence or presence of LPS for 4 (A, D), 8 (B, E) and 18 (C, F) $\mathrm{hr}$. The data from 4 to 5 different specimens are shown. The expression of IL-12 and GAPDH was examined by quantitative real-time PCR. The level of IL-12 mRNA in the DH82 cells is given as the fold increase relative to the level of GAPDH mRNA in the DH82 cells. ** $P<0.01$, when compared with untreated DH82 cells. ${ }^{\#} P<0.01$, when compared with LPS-treated DH82 cells.

cytokines, LPS concentration used in these previous studies is extremely high compared to physiological conditions. In addition, incubation time used in these previous studies is 24 $\mathrm{hr}$ or more. We think that it is very important to evaluate interaction under the condition of low concentration and short treatment, in addition to the condition of high concentration and long treatment. It is possible that responses obtained from high concentration and long treatment of LPS were looked as pathological aspect. In this study, we are able to look LPS at $100 \mathrm{ng} / \mathrm{m} l$ and $4 \mathrm{hr}$ treatment time as prepathological aspect and/or early stage of infection. From this point of view, adenosine overall inhibited the production of inflammatory cytokines in canine macrophages treated with LPS at low concentration and short treatment in this study as well as human and mouse macrophages treated with LPS high concentration and long treatment. The question of whether adenosine-potentiated production of IL-6 and TNF- $\alpha$ at $18 \mathrm{hr}$ participates in the inflammatory or antiinflammatory responses remains to be addressed before drawing any conclusions. In canine macrophages, nonetheless, adenosine-potentiated production of IL- 6 and TNF- $\alpha$ at $18 \mathrm{hr}$ may contribute to host defense. Regarding IL-10, adenosine potentiated it in canine macrophages in this study and human monocytes, whereas adenosine inhibited it in mouse macrophages. It is likely that adenosine plays as anti-inflammatory cytokine in canine and human. From the LPS concentration's point of view, canine macrophages, human monocytes, and mouse macrophages were used at $100 \mathrm{ng} / \mathrm{ml}, 1 \mu \mathrm{g} / \mathrm{ml}$, and $100 \mu \mathrm{g} / \mathrm{m} l$ of LPS, respectively. It is possible that adenosine may potentiate IL-10 production under the lower concentration of LPS, whereas adenosine may inhibit it under high concentration of LPS. In contrast, ATP has been shown to inhibit the production of TNF- $\alpha$ and IL-12 by mouse macrophages treated with LPS at 10 $\mu \mathrm{g} / \mathrm{m} l$ for $24 \mathrm{hr}$ [13]. Our findings in this study also showed that ATP inhibited the production of IL-6, TNF- $\alpha$ and IL-12 in canine macrophages as well as mouse macrophages. We have confirmed that adenosine at concentrations of up to $10^{-3} \mathrm{M}$ and ATP at concentrations of up to $10^{-3} \mathrm{M}$ both failed to result in cell death in DH82 cells. From this point of view, we can exclude the possibility that the inhibitory effect of adenosine and ATP on the LPS-induced cytokine production results in the decrease of cell number.

Macrophages are components of innate or natural immune mechanisms, while lymphocytes are components of acquired or specific immune mechanisms. However, innate 
(A)

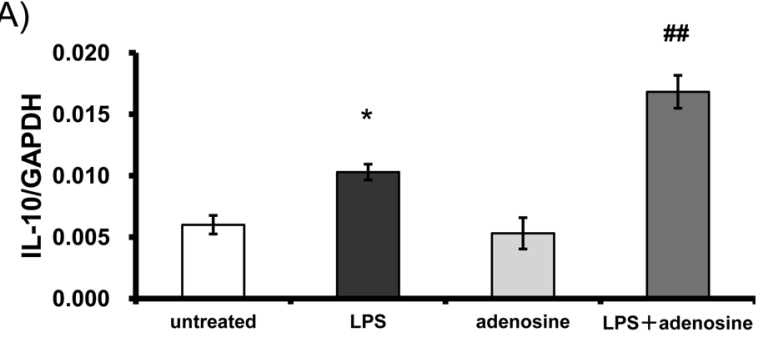

(B)

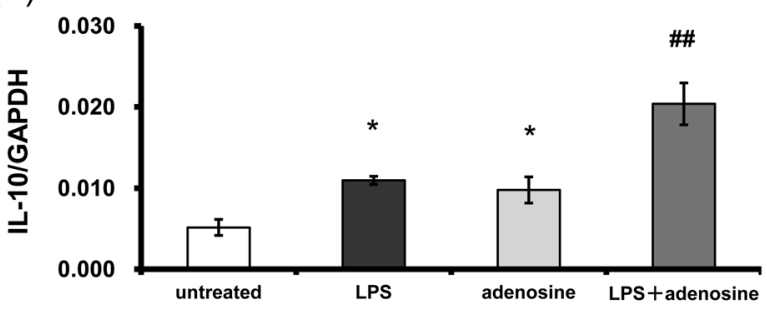

(C)

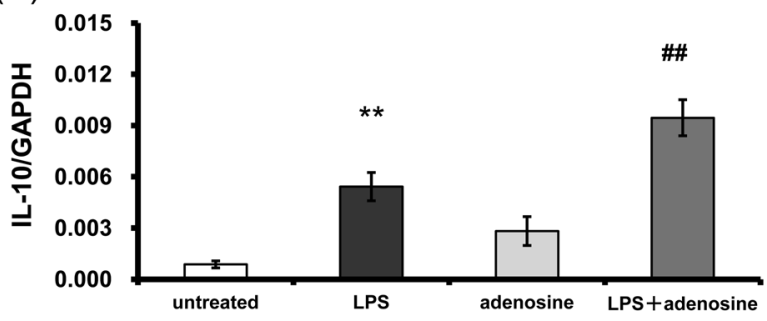

(D)

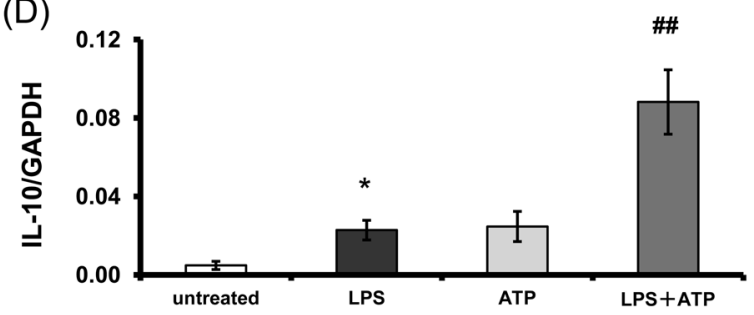

(E)

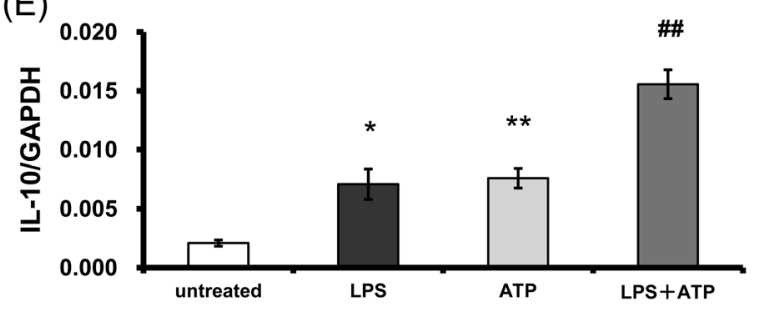

(F)

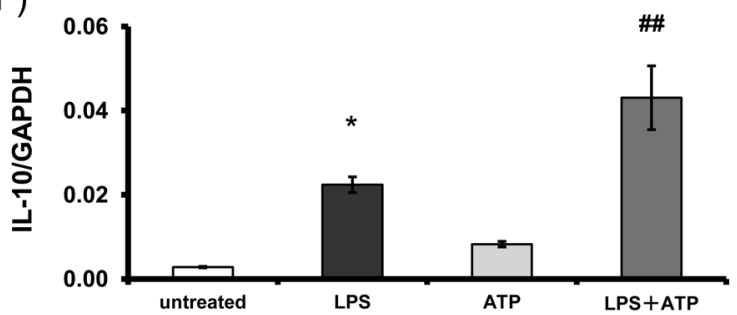

Fig. 5. Abilities of adenosine and ATP on the production of IL-10 in DH82 cells. DH82 cells were allowed to adhere to plates for 30 min. Adherent DH82 cells were incubated with adenosine or ATP in either the absence or presence of LPS for 4 (A, D), 8 (B, E) and 18 (C, F) $\mathrm{hr}$. The data from 3 to 6 different specimens are shown. The expression of IL-10 and GAPDH was examined by quantitative real-time PCR. The level of IL-10 mRNA in the DH82 cells is given as the fold increase relative to the level of GAPDH mRNA in the DH82 cells. * $P<0.05,{ }^{* *} P<0.01$, when compared with untreated DH82 cells. ${ }^{\#} P<0.01$, when compared with LPS-treated DH82 cells.

and specific immunity are not autonomous. This can be mediated through cytokines released by macrophages/ monocytes that play a critical role in influencing the Th1/ Th2 balance which, in turn, dictates the type of immune response generated. Thus, IL-12 activates T-cells and NK cells to proliferate, produce IFN $\gamma$, and lyse target cells [30], and also is a central inducer of cell-mediated immunity by promoting the development, proliferation and function of Th1 cells [16], while IL-10 downregulates these functions, and instead stimulates B-cell maturation [25]. IL-12 production is suppressed by IL-10 and IL-4, while IL-10 production is inhibited by IL-12 and IFN $\gamma$. It thus appears that conditions related to increased adenosine and/or ATP may play an important role in a wide range of immune reactions including the Th1 and Th2 immune response. In the absence of LPS, adenosine and ATP increased the production of IL-10 without affecting the production of IL-6, TNF$\alpha$ and IL-12, suggesting that adenosine and ATP might affect Th1 and Th2 immune responses independent of inflammatory responses.

It is shown that ATP is readily degraded to adenosine. Is there the possibility that the effect of ATP has mirrored the effect of adenosine? In the result of IL-6 production, adenosine, but not ATP, inhibited LPS-induced IL-6 production at 4 and $8 \mathrm{hr}$. At $18 \mathrm{hr}$, adenosine did not inhibit LPSinduced IL-6 production, but ATP inhibited it. It is likely that adenosine degraded from ATP may inhibit IL-6 production under the condition of $18 \mathrm{hr}$ incubation. These results suggest that ATP receptors did not affect IL-6 production, and adenosine receptors mediated to inhibit it. Another possibility is that the activation of adenosine receptors inhibits IL-6 production in early, and the activation of ATP receptors inhibits it in late-time windows. In the result of TNF- $\alpha$ production, adenosine and ATP inhibited it at 4 and $8 \mathrm{hr}$. At $18 \mathrm{hr}$, ATP but not adenosine inhibited TNF- $\alpha$ production. It cannot distinguish adenosine (degraded from ATP)-inhibited production from ATP-inhibited production. At $18 \mathrm{hr}$, at least, it is likely that ATP inhibited it via ATP receptor, because adenosine potentiated it. In the result of IL-12, adenosine and ATP inhibited it at 4 and $8 \mathrm{hr}$. At $18 \mathrm{hr}$, adenosine but not ATP inhibited IL-12 production, indicating that ATP-mediated inhibition would be due to via ATP receptor. Nonetheless, our results indicated that adenosine and ATP have an important role in the attenuation of inflammation. 


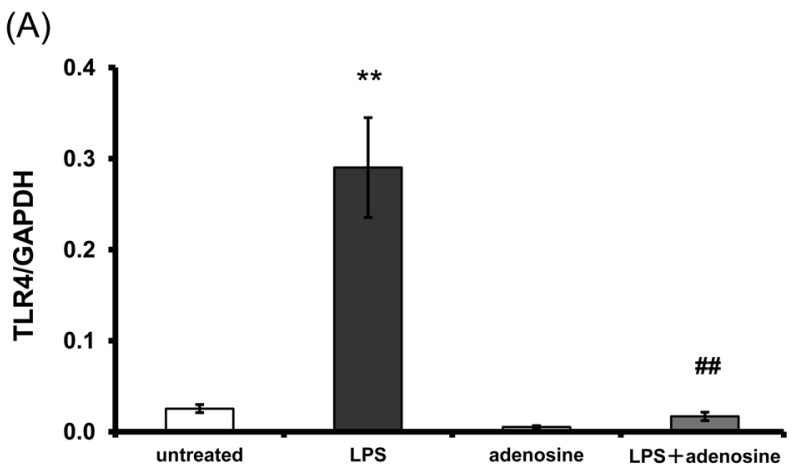

(B)

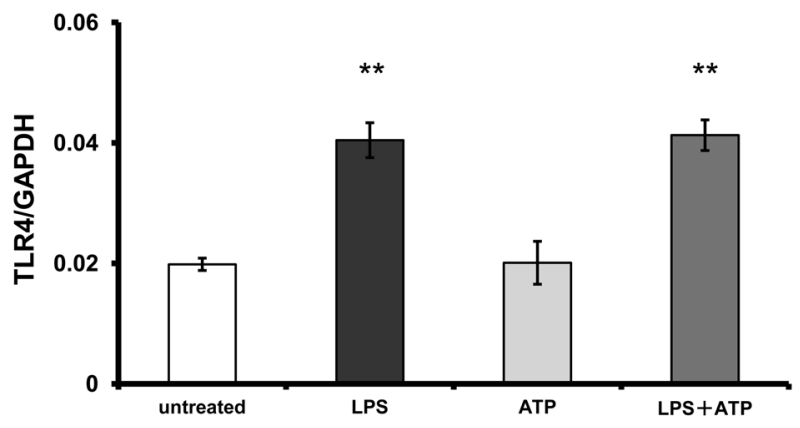

Fig. 6. Abilities of adenosine and ATP on the expression of TLR4 in DH82 cells. DH82 cells were allowed to adhere to plates for 30 min. Adherent DH82 cells were incubated with adenosine (A) or ATP (B) in either the absence or presence of LPS for $4 \mathrm{hr}$. The data from 3 to 5 different specimens are shown. The expression of TLR4 and GAPDH was examined by quantitative real-time PCR. The level of TLR4 mRNA in the DH82 cells is given as the fold increase relative to the level of GAPDH mRNA in the DH82 cells. ** $P<0.01$, when compared with untreated DH82 cells. ${ }^{\#} P<0.01$, when compared with LPS-treated DH82 cells.

The uniqueness of the adenosine and ATP may lie in the physiology of accumulation of abundant and ubiquitous purine nucleotides $[10,19]$ in the local inflammatory environment

How do adenosine and ATP alter the cytokine production? Adenosine and ATP have been shown to modulate IкB expression, thus preventing nuclear p50/p65 NF- $\mathrm{kB}$ translocation and arresting their nuclear transcriptional activity. NF- $\kappa B$ activation induces the transcription of many inflammatory cytokine genes, including IL-6, TNF- $\alpha$, IL-12 and IL-10. These results suggest that adenosine and ATP can modulate the expression of inflammatory cytokines through the regulation of NF- $\mathrm{KB}$ pathways. A further issue raised by the current work is to determine the translocation of nuclear $\mathrm{p} 50 / \mathrm{p} 65 \mathrm{NF}-\mathrm{\kappa B}$ in response to adenosine or ATP.

We also indicated that TLR4 are expressed on DH82 cells. Namely, LPS potentiated the expression of its own receptor TLR4. Several studies showed that LPS up-regu- lates TLR4 in human monocytes and neutrophils [2, 20, 21], but down-regulates TLR4 in mouse peritoneal macrophages $[22,32]$. The question of whether treatment with LPS participates in the up-regulation or down-regulation of the expression of TLR4 remains to be addressed in canine macrophages. In the present study, we focused on canine macrophages cell line DH82 cells, and observed that LPS upregulates the expression of TLR4. The second importance of the results described in this paper is that the adenosine, but not ATP, evidently inhibited LPS-induced expression of TLR4 in DH82 cells. It is shown that ATP is readily degraded to adenosine, suggesting that this study may distinguish the effect of adenosine from the effect of ATP. Naturally, potentiation of the expression of TLR4 resulted in deterioration of inflammation. Interestingly, adenosine potentiated the expression level of LPS-induced IL-10 production at $4 \mathrm{hr}$, although adenosine inhibited LPS-induced TLR4 production at $4 \mathrm{hr}$. In health host, TLR4 physiologically contributes to the recognition of pathogens. In contrast, the contents of IL-10 maintain to very low or almost none. From this point of view, adenosine prevented LPSmediated signals via down-regulation of TLR4, and potentiated IL-10 production as anti-inflammatory signals, indicating that adenosine plays as anti-inflammatory mediator. It is possible that IL-10 production was first induced, and then TLR4 expression was down-regulated in canine macrophage treated with adenosine within $4 \mathrm{hr}$. It is likely that adenosine may contribute to the attenuation of inflammation through the inhibition of TLR4 expression as well as the inhibition of inflammatory cytokine production.

It thus appears that adenosine and ATP modulate LPSinduced cytokine production in canine macrophages. Inappropriate or prolonged inflammation is the main cause of many diseases. It is important to understand the physiological mechanisms that terminate inflammation.

\section{REFERENCES}

1. Azuma, Y. T., Nishiyama, K., Matsuo, Y., Kuwamura, M., Morioka, A., Nakajima, H. and Takeuchi, T. 2010. PPAR $\alpha$ contributes to colonic protection in mice with DSS-induced colitis. Int. Immunopharmacol. 10: 1261-1267.

2. Azuma, Y. and Ohura, K. 2002. Evdomorphin-2 modulates productions of TNF- $\alpha$, IL- $1 \beta$, IL-10 and IL-12, and alters functions related to innate immune of macrophages. Inflammation 26: 223-232.

3. Azuma, Y., Watanabe, K., Date, M., Daito, M. and Ohura, K. 2004. Possible involvement of p38 in mechanisms underlying acceleration of proliferation by 15 -deoxy- $\Delta^{12,14}$-prostaglandin $\mathrm{J}_{2}$ and the precursors in leukemia cell line THP-1. J. Pharmacol. Sci. 94: 261-270.

4. Cronstein, B. N. 1994. Adenosine, an endogenous anti-inflammatory agent. J. Appl. Physiol. 76: 5-13.

5. Cronstein, B. N. 1995. A novel approach to the development of anti-inflammatory agents: adenosine release at the inflamed sites. J. Invest. Med. 43: 50-57.

6. Di Virgilio, F., Chiozzi, P., Falzoni, S., Ferrari, D., Sanz, J. M., Venketaraman, V. and Baricordi, O. R. 1998. Cytolytic P2X purinoceptors. Cell Death Differ. 5: 191-199. 
7. Eigler, A., Greten, T. F., Sinha, B., Haslberger, C, Sullivan, G. W. and Endres, S. 1997. Endogenous adenosine curtails lipopolysaccharide- stimulated tumor necrosis factor synthesis. Scand. J. Immunol. 45: 132-139.

8. Filippini, A., Taffs, R. E. and Sitkovsky, M. V. 1990. Extracellular ATP in T-lymphocyte activation: possible role in effector functions. Proc. Natl. Acad. Sci. U.S.A. 87: 8267-8271.

9. Firestein, G. S., Boyle, D., Bullough, D. A., Gruber, H. E., Sajjadi, F. G., Montag, A., Sambol, B. and Mullane, K. M. 1994. Prospective effect of an adenosine kinase inhibitor in septic shock. J. Immunol. 152: 5853-5859.

10. Fredholm, B.B., Arslan, G., Halldner, L., Kull, B., Schulte, G. and Wasserman, W. 2000. Structure and function of adenosine receptors and their genes. Naunyn-Schmiedeberg's Arch. Pharmacol. 362: 364-374.

11. Haskó, G., Szabó, C., Németh, Z. H., Kvetan, V., Pastores, S. M. and Vizi, E. S. 1996. Adenosine receptor agonists differentially regulate IL-10, TNF- $\alpha$, and nitric oxide production in RAW 264.7 macrophages and in endotoxemic mice. J. Immunol. 157: 4634-4640.

12. Haskó, G., Kuhel, D. G., Chen, J. F., Schwarzschild, M. A., Deitch, E.A., Mabley, J. G., Marton, A. and Szabó, C. 2000. Adenosine inhibits IL-12 and TNF- $\alpha$ production via adenosine A2a receptor-dependent and independent mechanisms. FASEB J. 14: 2065-2074.

13. Haskó, G., Kuhel, D. G., Salzman, A. L. and Szabó, C. 2000. ATP suppression of interleukin-12 and tumor necrosis factor- $\alpha$ release from macrophages. Br. J. Pharmacol. 129: 909-914.

14. Hoskin, D. W., Reynolds, T. and Blay, J. 1994. Adenosine as a possible inhibitor of killer T-cell activation in the microenvironment of solid tumors. Int. J. Cancer 59: 854-855.

15. Huang, S., Apasov, S., Koshiba, M. and Sitkovsky, M. 1997. Role of A2a adenosine receptor-mediated signaling in inhibition of T cell activation and expansion. Blood 90: 1600-1610.

16. Kobayashi, M., Fitz, L., Ryan, M., Hewick, R. M., Clark, S. C., Chan, S., Loudon, R., Sherman, F., Perussia, B. and Trinchieri, G. 1989. Identification and purification of natural killer cell stimulatory factor (NKSF), a cytokine with multiple biologic effects on human lymphocytes. J. Exp. Med. 170: 827-845.

17. Link, A.A., Kino, T., Worth, J. A., McGuire, J. L., Crane, M. L., Chrousos, G. P, Wilder, R.L. and Elenkov, I. J. 2000. Ligand-activation of the adenosine A2a receptors inhibits IL12 production by human monocytes. J. Immunol. 164: 436442.

18. Marquardt, D. L., Gruber, H. E. and Wasserman, S. I. 1984. Adenosine release from stimulated mast-cells. Proc. Natl. Acad. Sci. U.S.A. 81: 6192-9196.

19. Medvedev, A. E., Kopydlowski, K. M. and Vogel, S. N. 2000. Inhibition of lipopolysaccharide-induced signal transduction in endotoxin-tolerized mouse macrophages: dysregulation of cytokine, chemokine, and toll-like receptor 2 and 4 gene expression. J. Immunol. 164: 5564-5574.

20. Muzio, M., Bosisio, D., Polentarutti, N., D'amico, G., Stoppacciaro, A., Mancinelli, R., Veer, C. V., Penton-Rol, G., Ruco, L. P., Allavena, P. and Mantovani, A. 2000. Differential expression and regulation of toll-like receptors (TLR) in human leukocytes: selective expression of TLR3 in dendritic cells. $J$. Immunol. 164: 5998-6004.

21. Muzio, M., Natoli, G., Saccani, S., Levrero, M. and Mantovani, A. 1998. The human toll signaling pathway: divergence of nuclear factor $\kappa \mathrm{B}$ and JNK/SAPK activation upstream of tumor necrosis factor receptor-associated factor 6 (TRAF6). $J$. Exp. Med. 187: 2097-2101.

22. Nomura, F., Akashi, S., Sakao, Y., Sato, S., Kawai, T., Matsumoto, M., Nakanishi, K., Kimoto, M., Miyake, K., Takeda, K. and Akira, S. 2000. Endotoxin tolerance in mouse peritoneal macrophages correlates with down-regulation of surface tolllike receptor 4 expression. J. Immunol. 164: 3476-3479.

23. Ohta, A. and Sitkovsky, M. 2001. Role of G-protein-coupled adenosine receptors in downregulation of inflammation and protection from tissue damage. Nature 414: 916-920.

24. Ralevic, A. and Burnstock, G. 1998. Receptors for purines and pyrimidines. Pharmacol. Rev. 50: 413-492.

25. Rousset, F., Garcia, E., Defrance, T., Péronne, C., Vezzio, N., Hsu, D. H., Kastelein, R., Moore, K. W. and Banchereau, J. 1992. Interleukin 10 is a potent growth and differentiation factor for activated human B lymphocytes. Proc. Natl. Acad. Sci. U.S.A. 89: 1890-1893.

26. Rudolphi, K. A., Schubert, P., Parkinson, F. E. and Fredholm, B. B. Neuroprotective role of adenosine in cerebral ischemia. Trends Pharmacol. Sci. 13: 439-445.

27. Sullivan, G. W., Sarembock, I. J. and Linden, J. 2000. The role of inflammation in vascular diseases. J. Leukoc. Biol. 67: 591602.

28. Surprenant, A., Rassendren, F., Kawashima, E., North, R. A. and Buell, G. 1996. The cytolytic P2Z receptor for extracellular ATP identified as a $\mathrm{P} 2 \mathrm{X}$ receptor $(\mathrm{P} 2 \mathrm{X} 7)$. Science 272: 735-738.

29. Szabó, C., Scott, G. S., Virág, L., Egnaczyk, G., Salzman, A. L., Shanley, T. P. and Haskó, G. 1998. Suppression of macrophage inflammatory protein (MIP)- $1 \alpha$ production and collagen-induced arthritis by adenosine receptor agonists. $\mathrm{Br}$. $J$. Pharmacol. 125: 379-387.

30. Trinchieri, G. 1994. Interleukin-12: a cytokine produced by antigen-presenting cells with immunoregulatory functions in the generation of T-helper cells type 1 and cytotoxic lymphocytes. Blood 84: 4008-4027.

31. Van Belle, H., Goossens, F. and Wynants, J. 1987. Formation and release of purine catabolites during hypoperfusion, anoxia, and ischemia. Am. J. Pathol. 252: H886-H893.

32. Visintin, A., Mazzoni, A., Spitzer, J. H., Wyllie, D. H., Dower, S. K. and Segal, D. D. 2001. Regulation of toll-like receptors in human monocytes and dendritic cells. J. Immunol. 166: 249255.

33. Winn, H. R., Rubio, R. and Berne, R. M. 1981. Brain adenosine concentration during hypoxia in rat. Am. J. Physiol. 241: $\mathrm{H} 235-\mathrm{H} 242$.

34. Wright, S. D., Ramos, R. A., Tobias, P. S., Ulevitch, R. J. and Mathison, J. C. 1990. CD14, a receptor for complexes of lipopolysaccharide (LPS) and LPS binding protein. Science 249: 1431-1433.

35. Wright, S. D., Ramos, R. A., Hermanowski-Vosatka, A., Rockwell, P. and Detmers, P. A. 1991. Activation of the adhesive capacity of CR3 on neutrophils by endotoxin: dependence on lipopolysaccharide binding protein and CD14. J. Exp. Med. 173: $1281-1286$.

36. Xaus, J., Mirabet, M., Lloberas, J., Soler, C., Lluis, C., Franco, R. and Celada, A. 1999. IFN- $\gamma$ up-regulates the A2b adenosine receptor expression in macrophages: a mechanism of macrophage deactivation. J. Immunol. 162: 3607-3614. 